\title{
Unexpected Phytostimulatory Behavior for Escherichia coli and Agrobacterium tumefaciens Model Strains
}

\author{
Vincent Walker, Maxime Bruto, Floriant Bellvert, René Bally, Daniel Muller, Claire Prigent-Combaret, \\ Yvan Moënne-Loccoz, and Gilles Comte
}

Université de Lyon, F-69622, Lyon, France; Université Lyon 1, Villeurbanne, France; and CNRS, UMR5557, Ecologie

Microbienne, Villeurbanne, France.

Submitted 23 December 2012. Accepted 3 January 2013.

\begin{abstract}
Plant-beneficial effects of bacteria are often underestimated, especially for well-studied strains associated with pathogenicity or originating from other environments. We assessed the impact of seed inoculation with the emblematic bacterial models Agrobacterium tumefaciens C58 (plasmid-cured) or Escherichia coli $\mathrm{K}-12$ on maize seedlings in nonsterile soil. Compared with the noninoculated control, root biomass (with A. tumefaciens or $E$. coli) and shoot biomass (with $A$. tumefaciens) were enhanced at 10 days for 'PR37Y15' but not 'DK315', as found with the phytostimulator Azospirillum brasilense UAP-154 (positive control). In roots as well as in shoots, Agrobacterium tumefaciens and $E$. coli triggered similar (in PR37Y15) or different (in DK315) changes in the high-performance liquid chromatography profiles of secondary metabolites (especially benzoxazinoids), distinct from those of Azospirillum brasilense UAP-154. Genome sequence analysis revealed homologs of nitrite reductase genes nirK and nirBD and siderophore synthesis genes for Agrobacterium tumefaciens, as well as homologs of nitrite reductase genes nirBD and phosphatase genes phoA and appA in $E$. coli, whose contribution to phytostimulation will require experimental assessment. In conclusion, the two emblematic bacterial models had a systemic impact on maize secondary metabolism and resulted in unexpected phytostimulation of seedlings in the Azospirillum sp.-responsive cultivar.
\end{abstract}

In soil, plant roots are colonized by a wide range of bacteria (Sanguin et al. 2006b). They include strains with contrasted types of interactions with the plant, and whose effects on the host are neutral, phytopathogenic or deleterious, or plant beneficial (Raaijmakers et al. 2009). Among the latter, plant growth-promoting rhizobacteria (PGPR) play an important role (Lucy et al. 2004), because they may enhance root system development, nutrient and water uptake, stress tolerance, or plant health (Raaijmakers et al. 2009; Richardson et al. 2009).

Often, the distinction between plant-beneficial bacteria and the other bacteria is not straightforward, because i) certain taxa contain both types of strains (Blakney and Patten 2011; Sanguin

Corresponding author: G. Comte; E mail: gilles.comte@univ-lyon1.fr

* The $\boldsymbol{e}$-Xtra logo stands for "electronic extra" and indicates that a supplementary table is published online.

(C) 2013 The American Phytopathological Society et al. 2008), ii) the positive effects of certain plant-beneficial strains are small (Sharifi-Tehrani et al. 1998), iii) PGPR strains may not express their plant-beneficial potential depending on experimental conditions (Mark et al. 2005), or iv) certain PGPR strains might even have (small) negative effects in particular conditions (Rezzonico et al. 2007). It is an interesting scientific issue to understand which bacteria can have PGPR effects, as well as when and how.

In this context, it may be useful in certain experiments to have access to negative inoculation controls (i.e., bacteria without any PGPR behavior). Our rationale (which proved unsuccessful) was that bacteria without PGPR potential may be found among i) root-colonizing bacterial pathogens in which virulence functions were eliminated or ii) saprophytic gut bacteria ill-adapted to soil ecosystems. On this basis, we assessed two well-studied bacterial models for which the discovery of a possible plant-beneficial behavior was particularly unexpected but found that both actually behaved as such following seed inoculation of maize.

One of these two well-studied bacterial models was the phytopathogen Agrobacterium tumefaciens C58. The Agrobacterium genus colonizes the maize rhizosphere extensively (Sanguin et al. 2006b) but it does so as a saprophyte because it does not induce disease in monocots, and the benzoxazinoid compound HDMBOA (2-hydroxy-4,7-dimethoxybenzoxazin3 -one) in roots and root exudates of maize inhibits vir expression (Zhang et al. 2000). Certain A. tumefaciens strains naturally lack virulence plasmids and are avirulent to susceptible dicot hosts (Hao et al. 2011; Raio et al. 2004). The tumorinducing strain C58 was isolated from a cherry tree gall but this genotype has also been found in soils elsewhere (Costechareyre et al. 2010). This strain is the main Agrobacterium model for pathogenicity studies and is a reference strain for taxonomy assessments (Lassalle et al. 2011; Portier et al. 2006).

The other well-studied bacterial model we included is $E s$ cherichia coli K-12 (Bachmann 1987). E. coli is not expected to be adapted to soil, even though we found that certain genotypes of this species were natural rhizosphere inhabitants in family Poaceae-based alpine meadows (Texier et al. 2008). Strain K-12 was isolated from the stool of a convalescent diphtheria patient in 1922 (Jensen 1993).

The objective of this work was to assess the plant-beneficial effects of the bacterial models A. tumefaciens C58 (plasmidfree) and $E$. coli K-12 on maize. To this end, the strains were inoculated singly to maize seed and grown in nonsterile soil under greenhouse conditions. Three Azospirillum strains iso- 
lated from maize were also included as positive PGPR controls. The effect of inoculation on plant growth was assessed, in comparison with a noninoculated control. In addition, inoculation effects on maize secondary metabolites were investigated by high-performance liquid chromatography (HPLC) profiling, because inoculation with Azospirillum PGPR strains resulted in significant changes in secondary metabolic profiles of roots and shoots, corresponding to a modulation in the content of benzoxazinoids (Walker et al. 2011, 2012). Finally, the genome sequences of $A$. tumefaciens $\mathrm{C} 58$ and $E$. coli $\mathrm{K}-12$ were assessed for presence of genes known to encode plantbeneficial functions in PGPR strains.

\section{RESULTS}

\section{Effect of inoculation on early plant growth.}

At 10 days, inoculation with A. tumefaciens GMI9023 increased biomass of maize 'PR37Y15' by 67\% (roots) and 90\% (shoots), in comparison with the noninoculated control (Fig. 1A). This increase in root biomass was equivalent to that induced by Azospirillum brasilense UAP-154, whereas the effects of the two other PGPR reference strains were not significant (Walker et al. 2011). For shoot biomass, the phytostimulation difference between Agrobacterium tumefaciens GMI9023 and the three Azospirillum strains was not significant. Inoculation with $E$. coli K-12 MG1655 increased root biomass of PR37Y 15 by $69 \%$ (which was equivalent to the effect of $A$. tumefaciens GMI9023 or Azospirillum brasilense UAP-154), but the impact on shoot biomass was not significant.

Neither Agrobacterium tumefaciens GMI9023 nor E. coli K-12 MG1655 had any effect on root or shoot biomass of maize 'DK315' (Fig. 1B). The same finding was made with the Azospirillum strains (Walker et al. 2011).

\section{Effect of inoculation}

\section{on secondary metabolic profiles of maize.}

HPLC analysis of methanolic extracts of maize PR37Y15 gave 45 (roots) and 57 (shoots) integrated chromatographic peaks at $280 \mathrm{~nm}$. Discriminant principal component analysis (PCA) for roots ( $51 \%$ data variability) indicated that inoculation with A. tumefaciens GMI9023 or E. coli K-12 MG1655 had a similar impact on root HPLC profile (Fig. 2A). This
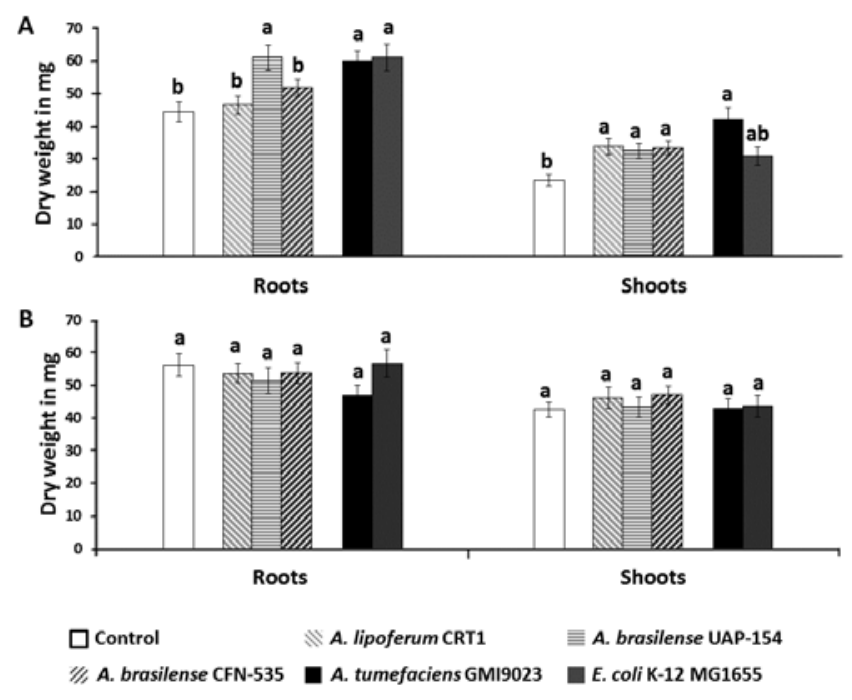

Fig. 1. Effect of inoculation on maize dry biomass at 10 days after sowing for A, 'PR37Y15. and B, 'DK315'. Different letters indicate significant differences between treatments (analysis of variance and Tukey's test; $P<$ $0.05)$. impact was also similar to that of Azospirillum brasilense UAP-154, especially in the case of Agrobacterium tumefaciens GMI9023, but clearly distinct from those of the two other Azospirillum strains. Discriminant PCA for shoots (52\% data variability) showed that inoculation with $A$. tumefaciens GMI9023 or E. coli K-12 MG1655 had an impact on shoot HPLC profile (Fig. 2C), and the impact of A. tumefaciens GMI9023 was similar to that of Azospirillum brasilense CFN535.

HPLC chromatograms obtained for root and shoot methanolic extracts of maize DK315 gave 45 and 47 integrated peaks, respectively. Discriminant PCA (48\% data variability for roots and for shoots) indicated that inoculation with Agrobacterium tumefaciens GMI9023 or E. coli K-12 MG1655 had an impact on maize HPLC profile, whereas Azospirillum inoculation had no or little effect on HPLC profile in comparison, regardless of whether roots (Fig. 2C) or shoots (Fig. 2D) were considered.

\section{Effect of inoculation \\ on individual secondary metabolites of maize.}

For PR37Y15, inoculation with A. tumefaciens GMI9023 or E. coli K-12 MG1655 had an impact on the prevalence of most PCA-discriminant secondary metabolites in roots or shoots, based on analysis of variance (ANOVA) and Tukey's tests. Indeed, A. tumefaciens inoculation increased root contents in the benzoxazinoid derivatives 2-(2,4-dihydroxy-7-methoxy-1,4benzoxazin-3-one)- $\beta$-D-glucopyranose (DIMBOA-Glc) and 2$\beta$-D-glucopyranosyloxy-4,7-dimethoxy-1,4-benzoxazin-3-one (HDMBOA-Glc), and decreased those in 2,4-dihydroxy-7methoxy-2H-1,4-benzoxazin-3(4H)-one (DIMBOA) and 6methoxybenzoxazolin-2-one (MBOA) (Fig. 3A), as well as increased shoot contents in DIMBOA-Glc and decreased those in MBOA, an unidentified benzoxazinoid ( $\mathrm{Bx} 1)$, and cinnamic acids 1 and 2 (Fig. 3C). For roots and shoots, the effects of E. coli K-12 MG1655 and A. tumefaciens GMI9023 on PCA-discriminant secondary metabolites were comparable. Their differences with the impacts of Azospirillum lipoferum CRT1 and especially $A$. brasilense CFN-535 were often minor, whereas inoculation with $A$. brasilense UAP-154 resulted mostly in opposite effects.

For DK315, inoculation with Agrobacterium tumefaciens GMI9023 or E. coli K-12 MG1655 had an impact on the prevalence of a majority of PCA-discriminant secondary metabolites. Agrobacterium inoculation increased root content in the benzoxazinoid derivative MBOA and decreased that in 6,7-dimethoxy-benzoxazolin-2-one ( $\left.\mathrm{M}_{2} \mathrm{BOA}\right)$ (Fig. 3B), whereas it increased shoot contents in $\mathrm{M}_{2} \mathrm{BOA}$ and an unidentified benzoxazinoid (Bx 2) and decreased that in DIMBOA (Fig. 3D). E. coli $\mathrm{K}-12 \mathrm{MG} 1655$ had effects similar to A. tumefaciens, except that it also reduced DIMBOA content in roots and enhanced MBOA content in shoots. In contrast with PR37Y15, the effects of the three Azospirillum strains on discriminant compounds in DK315 were rather similar, and they differed in many cases from the impacts of A. tumefaciens and E. coli inoculation.

\section{Occurrence of genes encoding plant-beneficial functions in PGPR.}

In A. tumefaciens C58, genome sequence analysis revealed i) a nitrite reductase-encoding nirK homolog located on the linear chromosome, in between nirV (Atu4381) and a gene (Atu4383) coding a putative nirK regulator of the NnrS family; ii) a second operon of nitrite reductase genes, corresponding to nirBD homologs; and iii) the nitrate reductase gene nasA (Table 1). Two genes for siderophore synthesis were also found. The genome exhibits $i a{ } H M$ on the pTi plasmid, but this work 
was done with a pTi-cured derivative of strain C58. A complete hcn operon was also found. Each of the Hcn homologs displayed the same functional domains found in established Hon sequences (but also in opine oxidases). However, their synteny was that of opine oxidase genes, suggesting that, in fact, the Hcn homologs belong to the opine oxidase family, in accordance with National Center for Biotechnology Information annotation. In summary, the only genes known to encode a potentially plant-beneficial function in PGPR strains that were found in A. tumefaciens C58 are homologs of i) nirK and nir $B D$, which code for dissimilatory nitrite reductases involved in production of the root branching signal nitric oxide; and ii) siderophore synthesis genes.

In $E$. coli $\mathrm{K}-12$, genome analysis identified i) nirBD nitrite reductase homologs (along with nitrate reductase homologs narGHJI and narVWYZ), as well as ii) alkaline phosphatase homolog phoA (along with other pho genes) and acid phosphatase/phytase homolog appA (Table 1). A homology search of AcdS (1-aminocyclopropane-1-carboxylic acid [ACC] deaminase) and its transcriptional regulator AcdR gave significant results by BlastP analysis, with proteins b1919 and b0889, respectively. However, functional annotation of the b1919 protein showed a pyridoxal-phosphate-dependent deaminase domain that is usually found in D-cysteine sulfhydrase proteins, in accordance with the annotation provided in GenBank classifying b1919 as a D-cysteine desulfhydrase. Moreover, this protein lacks the conserved amino acids E296 and L323 found in bona fide ACC deaminase. Similarly, protein b0889 is likely a feast/famine regulatory protein (Yokoyama and Suzuki 2005) but is distinct from AcdR (Prigent-Combaret et al. 2008). In summary, homologs of nitrite reductase genes nirBD and phosphatase genes $p h o A$ and appA were found in E. coli $\mathrm{K}-12$ genome.

\section{DISCUSSION}

Unexpectedly, seed inoculation of maize with A. tumefaciens or E. coli enhanced shoot (only at $P<0.10$ for $E$. coli) and root biomass of PR37Y15. The two species are usually studied as pathogens of plants (Krimi et al. 2002) and humans (Fremaux et al. 2008), respectively. However, both display significant genetic diversity (Lassalle et al. 2011; Tenaillon et al. 2010) and include nonpathogenic strains (Hao et al. 2011; Tenaillon et al. 2010), a situation also documented in the Pseudomonas syringae species complex (Blakney and Patten 2011; Mohr et al. 2008).

Nonpathogenic A. tumefaciens strains are saprophytic and can colonize the rhizosphere (Sanguin et al. 2006a) but, to our knowledge, this is the first evidence of A. tumefaciens functioning as plant-beneficial bacteria in a plant experiment carried out in nonsterile soil. A. tumefaciens D3 promoted canola root elongation, as did strain GR12-2 from (or close to) the $P$. syringae complex, but these canola experiments were under soil-less gnotobiotic conditions (Blakney and Patten 2011; Hao et al. 2011). Similarly, A. tumefaciens CCNWGS0286 enhanced Robinia spp. growth in sterile vermiculite (Hao et al. 2012). The occurrence of root-colonizing bacteria from E. coli has been rarely reported (Nautiyal et al. 2010; Texier et al. 2008), and phytostimulation capacity has only been described with soil isolates of this species (Nautiyal et al. 2010) and not model strains of clinical origin such as strain K-12. Here, it remains to be established to which extent A. tumefaciens
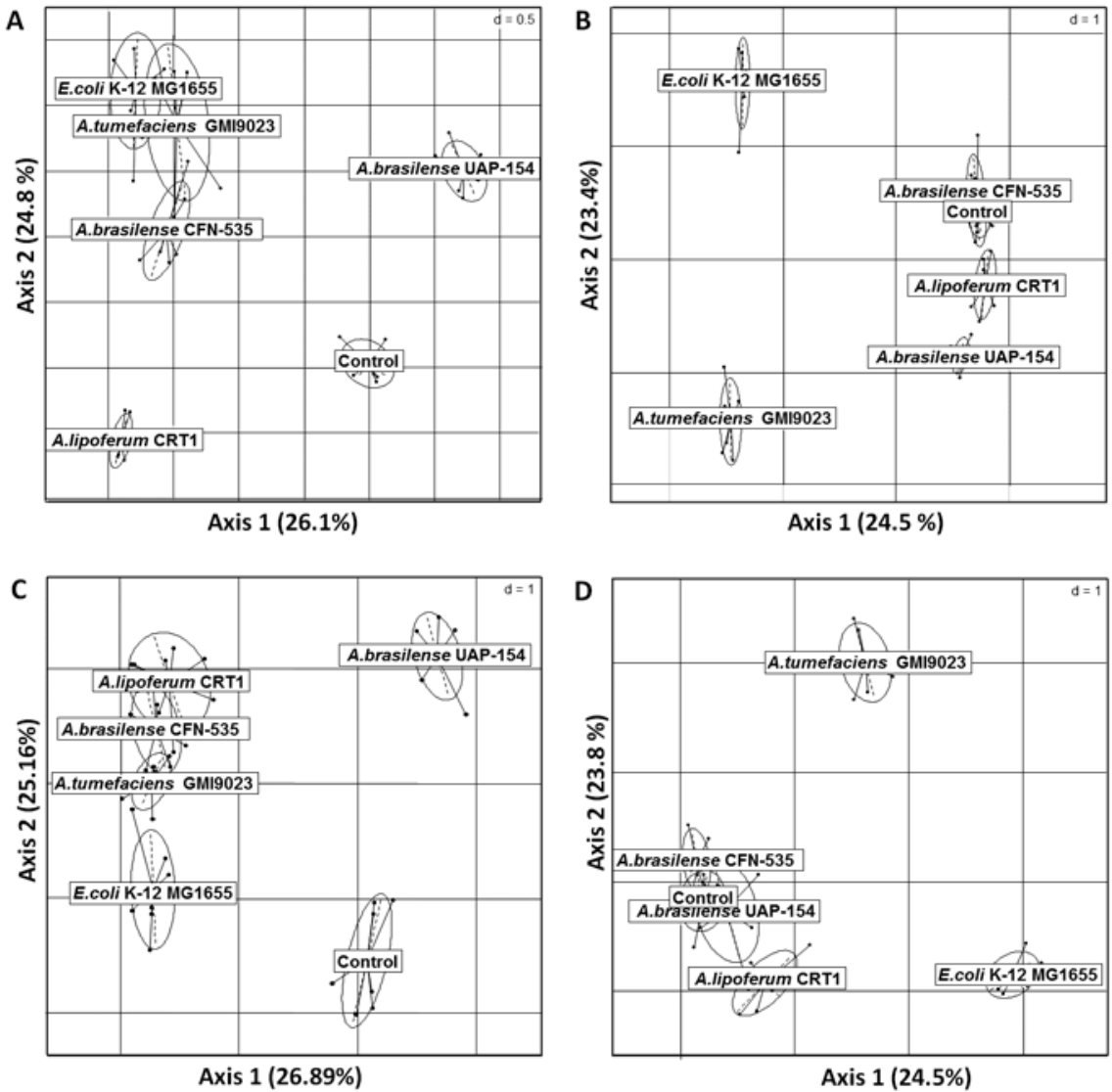

Fig. 2. Effect of inoculation on maize secondary metabolite profiles of roots of A, 'PR37Y15. and B, 'DK315', as well as shoots of $\mathbf{C}$, PR37Y15 and $\mathbf{D}$, DK315, based on discriminant principal component analysis performed on chromatograms obtained at 10 days for plant methanolic extracts. Analyses were done with the integration of peaks with a relative intensity up to $1 \%$ of the chromatogram. Each point represents four pooled extracts of the same treatment. 
GMI9023 or E. coli K-12 MG1655 can actually colonize maize roots in nonsterile soil, but certain PGPR (e.g., Azospirillum spp.) can manage to stimulate root growth even when inoculant cells are later removed by washing off seed (Jacoud et al. 1999).

Comparison with Azospirillum inoculation gave interesting insights. First, maize phytostimulation by A. tumefaciens or $E$. coli was of a magnitude similar to that of Azospirillum brasilense UAP-154 (the most effective Azospirillum PGPR strain) and (for roots of PR37Y15) was even superior to those of A. lipoferum CRT1 and A. brasilense CFN-535, two maize isolates that are well established as maize phytostimulators (Dobbelaere et al. 2001; Jacoud et al. 1999). In other words, the magnitude of their phytostimulation effect was rather high, whereas Agrobacterium tumefaciens D3 did not fare as well as the PGPR P. putida UW4 on canola (Hao et al. 2011). Second, neither A. tumefaciens nor E. coli had any effect on DK315, which did not respond to Azospirillum inoculation, either. This suggests that maize traits promoting receptivity to A. tumefaciens or $E$. coli phytostimulation might be the same as those required for Azospirillum spp.

Interestingly, inoculation of A. tumefaciens GMI9023 or E. coli K-12 MG1655 resulted in significant modifications in the secondary metabolite profile of maize. The effects of both inoculants on secondary metabolites of PR37Y15 were most similar to that of Azospirillum brasilense CFN-535 (even though the latter was less effective in terms of phytostimulation). This suggests that all three strains were recognized by this maize cultivar as belonging to the same "type" of microorganism. Because these effects were clearly distinct from those of the other A. brasilense strains (and of the PGPR P. fluorescens F113 but in a different experimental set-up) (not shown), it will be of interest to include a larger taxonomic range of PGPR strains in future assessments. More puzzling, perhaps, was the observation that Agrobacterium tumefaciens GMI9023 and E. coli K-12 MG1655 induced major, inoculant-specific changes in the secondary metabolite profile of maize DK315, even though they had no effect on plant biomass. It could be that the 10-day sampling was too early for plant-growth-promotion effects to materialize. By contrast, the metabolic changes induced by the Azospirillum PGPR strains on this cultivar were minor, if any. This could also mean that the host plant reacts faster to A. tumefaciens or E. coli inoculation than to Azospirillum strains. In any case, the lack of negative effect of inoculation on maize growth (based on plant biomass data) indicates that inoculation-induced changes in maize secondary metabolite contents were not detrimental for primary metabolism and plant growth. This contrasts with the common observation that plant growth is restricted while defense-related secondary metabolites are produced during phytopathogen interactions (Herms and Mattson 1992). Therefore, there was no apparent cost for the plant, probably because changes concerned the relative proportion of the various
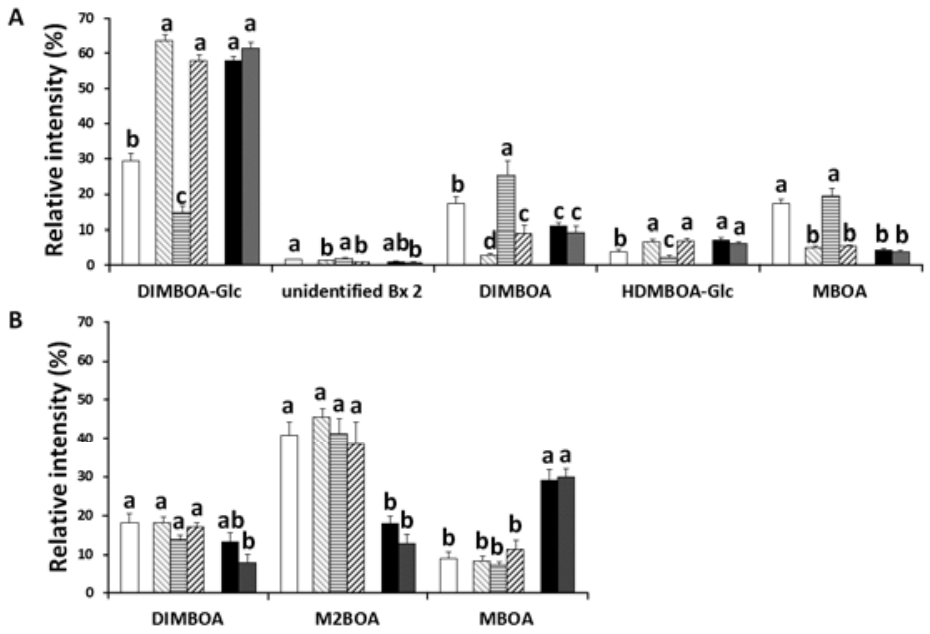

C

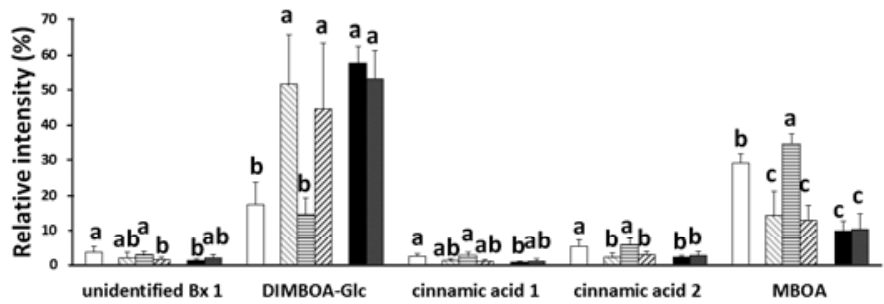

D

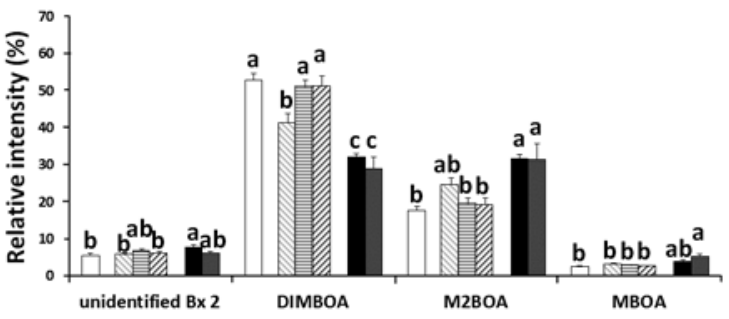

$\square$ Control $\mathbb{N}$ A. lipoferum CRT1 $\equiv$ A. brasilense UAP-154 ‥ A. brasilense CFN-535

Fig. 3. Effect of inoculation on prevalence at 10 days of discriminating secondary metabolites in roots of A, 'PR37Y15. and B, 'DK315', and in shoots of C, PR37Y15 and D, DK315. Bx, benzoxazinoid. Different letters indicate significant differences between treatments (analysis of variance and Tukey's test; $P<0.05)$. 
secondary metabolites rather than the total amount of secondary metabolites (Walker et al. 2011).

A. tumefaciens D3, which can promote canola root elongation under gnotobiotic conditions, displays the ACC deaminase gene acdS (Hao et al. 2011). Here, however, genome sequence analysis established that acdS was absent in A. tumefaciens GMI9023 (and E. coli K-12), confirming PCR sequencing results from Blaha and associates (2006). The genes known to encode a plant-beneficial function in PGPR strains and that were found here include homologs of nitrite reductase genes (in both strains), siderophore synthesis genes (in A. tumefaciens C58), and phosphatase genes (in E. coli K-12). The coppercontaining dissimilatory nitrite reductase gene nirK is expressed on roots (Pothier et al. 2007) and contributes to the stimulation of tomato lateral root formation via NO synthesis in Azospirillum brasilense Sp245 (Creus et al. 2005). The gene is expressed while Agrobacterium tumefaciens C58 is present on roots (Baek and Shapleigh 2005) but its role in phytostimulation remains to be ascertained. The genes involved in siderophore synthesis are also expressed on roots (Lassalle et al. 2011). In contrast, there is no information available thus far on rhizosphere expression of potentially plant-beneficial genes in E. coli or on their possible contribution to phytostimulation. Certain plantbeneficial traits may remain unnoticed for a long time in otherwise well-studied bacteria, including in PGPR strains (e.g., ACC deaminase activity in Azospirillum lipoferum $4 \mathrm{~B}$ and $P$. fluorescens F113) (Blaha et al. 2006), phosphate solubilization in P. fluorescens F113 (Miller et al. 2010), or NirK in A. brasilense Sp245 (Creus et al. 2005; Pothier et al. 2008).

Some of the effects of Agrobacterium tumefaciens GMI9023 and $E$. coli $\mathrm{K}-12$ MG1655 on maize growth and secondary metabolite profiles were rather similar to those of (at least some) Azospirillum strains. However, apart from NirK in A. tumefaciens GMI9023, the main plant-beneficial traits documented in Azospirillum spp. (i.e., associative nitrogen fixation) (Bashan et al. 2004), phytohormone production (Dobbelaere et al. 2003), and ACC deaminase activity (Prigent-Combaret et al. 2008), were not found.

\section{MATERIALS AND METHODS}

\section{Organisms.}

E. coli $\mathrm{K}-12$ MG1655 is a derivative of strain K-12 cured of its $\lambda$ phage (after UV light treatment) and $\mathrm{F}$ plasmid (after acridin orange treatment) (Jensen 1993). A. tumefaciens GMI9023 is a derivative of strain C58 cured of both pTiC58 and pAtC58 plasmids (Rosenberg and Huguet 1984). Strain C58 was isolated from a cherry tree gall (Hamilton and Fall 1971). It belongs to genomovar G8 of the A. tumefaciens complex (Mougel et al. 2002), a genomic species recently proposed as A. fabrum (Lassalle et al. 2011). PGPR controls were the maize isolates Azospirillum lipoferum CRT1 (Fages and Mulard 1988) and A. brasilense CFN-535 and UAP-154 (Dobbelaere et al. 2001). Maize lines included the semi-late hybrid PR37Y15 (Pioneer Semences SAS, Aussonne, France) and the semiearly hybrid DK315 (Monsanto SAS/Dekalb, St. Louis).

\section{Bacterial inoculation.}

Seed were surface-sterilized with a Bayrochlor mini solution (Bayrol at $3 \mathrm{~g} \mathrm{liter}^{-1}$; Bayrol, Planegg, Germany) for $15 \mathrm{~min}$ under magnetic stirring and rinsed four to six times with sterile water ( $1 \mathrm{~h}$ in total). They were pregerminated for $48 \mathrm{~h}$ at room temperature on $1 \%$ (vol/vol) water agar, which gave radicles approximately $1 \mathrm{~cm}$ (DK315) and 1 to $2 \mathrm{~mm}$ (PR37Y15) in length.

Escherichia and Agrobacterium strains were grown in LPG medium (Ponsonnet and Nesme 1994). Azospirillum strains were grown in Luria-Bertani medium (Sambrook et al. 1989) containing only $\mathrm{NaCl}$ at $5 \mathrm{~g} \mathrm{liter}^{-1}(\mathrm{LBm})$ and $\mathrm{Nfb}$ medium (Nelson and Knowles 1978) supplemented with 1/40 of LBm medium. Liquid precultures were prepared from log-phase colonies by incubation $\left(200 \mathrm{rpm}, 28^{\circ} \mathrm{C}\right)$ for 16 to $18 \mathrm{~h}$ until an optical density (OD) of 0.7 (at $600 \mathrm{~nm}$ ), and cultures for seed inoculation were obtained in the same way after transferring aliquots (E. coli and Agrobacterium tumefaciens, 0.5\% [vol/ vol]; CRT1 and CFN-535, 1\% [vol/vol]; and UAP-154, 2\% $[\mathrm{vol} / \mathrm{vol}])$ into fresh broth. After centrifugation $(8,000 \mathrm{rpm}$,

Table 1. List of putative plant growth-promoting rhizobacteria genes identified based on function search in MAGE and GenoList data bases

\begin{tabular}{|c|c|c|c|}
\hline Functions sought, proteins found & References for function in target strains & Gene names & Accession numbers \\
\hline \multicolumn{4}{|l|}{ Agrobacterium tumefaciens $^{\mathrm{a}}$} \\
\hline \multicolumn{4}{|l|}{ Nitrogen metabolism } \\
\hline Nitrate reductase & Not available & nasA & NP_356734 \\
\hline NADPH-dependent nitrite reductase & Not available & $\operatorname{nir} B D$ & NP_356732-NP_356733 \\
\hline $\mathrm{Cu}$-dependent nitrite reductase ${ }^{\mathrm{b}}$ & Baek and Shapleigh 2005 & $\operatorname{nirK}$ & NP_356273 \\
\hline \multicolumn{4}{|l|}{ Siderophore biosynthesis } \\
\hline Siderophore biosynthesis protein & Rondon et al. 2004 & Atu3670 & NP_356946 \\
\hline Polyketide synthase & Rondon et al. 2004 & Atu3672 & NP_356944 \\
\hline \multicolumn{4}{|l|}{ Escherichia coli } \\
\hline \multicolumn{4}{|l|}{ Phosphate metabolism } \\
\hline Acid phosphatase with phytase activity & Rodríguez et al. 2007 & appA & AAC74065 \\
\hline Alcaline phosphatase $\mathrm{c}^{\mathrm{C}}$ & Yang and Metcalf 2004 & phoA & AAC73486 \\
\hline \multicolumn{4}{|l|}{ Nitrogen metabolism } \\
\hline Nitrite reductase & Macdonald and Cole 1985 & $\operatorname{nir} B D$ & AAC76390-AAC76391 \\
\hline Nitrite transporter & Macdonald and Cole 1985 & $\operatorname{nirC}$ & AAC76392 \\
\hline Nitrate/nitrite transporter & DeMoss and Hsu 1991 & nark & AAC74307 \\
\hline Nitrate reductase 1 & Blasco et al. 1989 & narGHJI & AAC74308-AAC74311 \\
\hline Nitrate/nitrite transporter & Noji et al. 1989 & narU & AAD13433 \\
\hline Nitrate reductase 2 & Blasco et al. 1990 & $n a r V W Y Z$ & AAC74547-AAC74550 \\
\hline Nitrite reductase cytochrome c & Hussain et al. 1994 & $n r f A B C$ & AAC77040-AAC77042 \\
\hline Nitrite reductase membrane unit & Hussain et al. 1994 & $n r f D$ nrfE & AAC77043-AAD13457 \\
\hline Nitrite reductase heme lyase & Hussain et al. 1994 & $n r f F G$ & AAD13458-AAD13459 \\
\hline
\end{tabular}


$10 \mathrm{~min}$ ), the cells were washed twice in $10 \mathrm{mM}$ magnesium sulfate buffer and the suspensions adjusted to 3 to $5 \times 10^{8} \mathrm{CFU}$ $\mathrm{ml} \mathrm{liter}{ }^{-1}$ based on OD measurements. Pregerminated seed were soaked for $30 \mathrm{~min}$ in a cell suspension (giving $1 \times 10^{7}$ to $4 \times$ $10^{7} \mathrm{CFU}$ seed liter $^{-1}$ in inoculation treatments) or in sterile water (noninoculated control).

\section{Plant experiment.}

The plant experiment was described by Walker and associates (2011), who focused on method development for maize secondary metabolites and compared plant-beneficial effects of Azospirillum strains. E. coli and A. tumefaciens inoculants were included as additional treatments in this experiment and are the focus of this report.

Briefly, seedlings were placed into 2-liter pots filled with nonsterile loamy soil (16.2\% clay, $43.9 \%$ silt, $39.9 \%$ sand, $\mathrm{pH}$ 7.0 in water, and $2.1 \%$ organic matter) (El Zemrany et al. 2006) taken from the surface horizon of a luvisol at the experimental farm of La Côte St André (near Lyon, France) and sieved at $4 \mathrm{~mm}$. Each treatment was studied using eight pots containing four seedlings each, and the pots were kept (completely randomized design) in a greenhouse set at $20^{\circ} \mathrm{C}$ with $16 \mathrm{~h}$ of daylight ( $45 \%$ relative humidity) and $8 \mathrm{~h}$ of darkness (65\% relative humidity). Soil was maintained at $20 \%$ (wt/wt) water content.

\section{Sampling and plant analysis.}

At 10 days after inoculation, root systems were washed with water to discard soil adhering to roots. Each root system was dipped into liquid nitrogen (to avoid enzymatic reactions) and freeze dried for $72 \mathrm{~h}$ at $-54^{\circ} \mathrm{C}$. Shoots were processed the same. Dry plant biomass was then determined, and data were assessed by ANOVA and Tukey's tests $(P<0.05)$, using $\mathrm{R}$ software (v2.4 Open Source).

Chromatographic analysis was performed on freeze-dried roots and shoots, as described (Walker et al. 2011). Samples were placed in an Eppendorf tube, treated with liquid nitrogen, crushed using a ball mill (TissueLyser II; Qiagen S.A., Courtaboeuf, France), and extracted using $2 \mathrm{ml}$ of methanol for 10 $\mathrm{mg}$ of dry sample. Samples from two successive extractions were pooled, dried by Speedvac-assisted evaporation, and resuspended in methanol to obtain dry extract at $4 \mathrm{mg} \mathrm{ml}^{-1}$.

\section{HPLC analysis.}

HPLC analysis of root and shoot extracts was done as described by Walker and associates (2011), using an Agilent 1200 series HPLC equipped with a degasser (G132A), a quaternary pump module (G1311A), an automatic sampler (G1329A), and a Diode Array Detector (DAD G1315B). The separation was done at room temperature, using a NUCLEODUR sphinx C18 column (250 by $4.6 \mathrm{~mm}$ and $5 \mu \mathrm{m}$; Macherey-Nagel, Düren, Germany). Root extracts $(20 \mu \mathrm{l})$ were eluted from the column at $1 \mathrm{ml} \mathrm{min}^{-1}$, with an optimized step-by-step gradient obtained with solvents A (acetic acid $4 \%$ [vol/vol] in water) and B (acetic acid 4\%o [vol/vol] in acetonitrile) (Carloerba Reagents, Val de Reuil, France), increasing solvent B proportion up to $15 \%$ during $5 \mathrm{~min}$, followed with an isocratic level from 30 min (flux of $1 \mathrm{ml} \mathrm{min}^{-}$ $\left.{ }^{1}\right)$. For shoot extracts, separation was carried out with the same column, with a linear gradient of acetonitrile in water from 0 to $100 \%$ in $55 \mathrm{~min}$ (for PR37Y15) or 10 to $100 \%$ in 50 min (for DK315). Chromatograms were processed at 254, 280, 310, and $366 \mathrm{~nm}$, and integrated (after standardization and removal of background peaks) using Chemstation Agilent software. Data were obtained for the E. coli and A. tumefaciens inoculation treatments and consolidated with those of Walker and associates (2011) for the other treatments.
Retention time and relative intensity were recorded for each chromatographic peak (280 nm). PCA was done using R software (v2.4 Open Source).

\section{Liquid chromatography and mass spectrometry analysis.}

Compound separation for mass spectrometry processing of root and shoot extracts was done at room temperature with the NUCLEODUR sphinx C18 column (Macherey-Nagel), using an Agilent 1100 series HPLC equipped with a degasser (G1322A), a binary pump module (G1312A), an automatic sampler (G1313A), and a Diode Array Detector (DAD G1314A), as described (Walker et al. 2011, 2012). Mass spectrometry was done with a gas temperature of $350^{\circ} \mathrm{C}, \mathrm{N}_{2}$ flow rate of 10 liters $\mathrm{min}^{-1}$, nebulizer pressure of $30 \mathrm{psi}$, quadripole temperature of $30^{\circ} \mathrm{C}$, capillary voltage of $4,000 \mathrm{~V}$, and fragmentor 100. Full-scan spectra were recorded from m/z 100 to 800 in both positive and negative ion modes, and metabolites were identified based on mass spectrum. This analysis was done for the E. coli and A. tumefaciens inoculation treatments, to enable comparison with the results of Walker and associates (2011) obtained for the other treatments.

\section{Genome search for genes}

encoding plant-beneficial functions.

Whole-genome sequences and annotations of E. coli $\mathrm{K}-12$ MG1655 and A. tumefaciens C58 were collected from the European Bioinformatics Institute database. Two approaches were followed. First, 29 genes coding for the main phytobeneficial functions in PGPR were selected (Supplementary Table S1), and their protein sequences were retrieved from GenBank. Homologs were searched by BlastP (Altschul et al. 1997) in databases containing the coding DNA sequence identified in the two genomes, based on a threshold of $30 \%$ sequence identity over $70 \%$ of sequence length. In order to circumvent potential misleading or false annotations, a second search was done by TblastN (Altschul et al. 1997) when the BlastP search did not give any result. Functional annotation of putative homologs was performed using InterProscan (Zdobnov and Apweiler 2001). Comparison of identified domains between reference and candidate proteins was used to identify true homology and, thus, genes potentially coding for a phytobeneficial function. Second, genes were also sought in MAGE and Genolist databases, based on gene names or particular functions (i.e., "Siderophore synthesis", "Phosphate metabolism", "Nitrogen metabolism", and "Phenazine synthesis".

\section{ACKNOWLEDGMENTS}

This work was supported, in part, by the European Union (FW6 STREP project MicroMaize 036314). This work made use of the platforms CESN (UMR CNRS 5557 Ecologie Microbienne) and Serre (FR 41) in Université Lyon 1. We thank X. Nesme (from our laboratory) for supplying A. tumefaciens GMI9023 and D. Desbouchages (FR41, Université Lyon 1) for help with greenhouse experiments.

\section{LITERATURE CITED}

Altschul, S. F., Madden, T. L., Schäffer, A. A., Zhang, J., Zhang, Z., Miller, W., and Lipman, D. J. 1997. Gapped BLAST and PSI-BLAST: A new generation of protein database search programs. Nucleic Acids Res. 25:3389-3402.

Bachmann, B. J. 1987. Derivations and genotypes of some mutant derivatives of Escherichia coli K-12. Pages 1190-1219 In: Escherichia coli and Salmonella typhimurium: Cellular and Molecular Biology. F. C. Neidhardt, J. L. Ingraham, K. B. Low, B. Magasanik, M. Schaechter, and H. E. Umbarger, eds. ASM Press, Washington, DC.

Baek, S. H., and Shapleigh, J. P. 2005. Expression of nitrite and nitric oxide reductases in free-living and plant-associated Agrobacterium tumefaciens C58 cells. Appl. Environ. Microbiol. 71:4427-4436. 
Bashan, Y., Holguin, G., and de-Bashan, L. E. 2004. Azospirillum-plant relationships: Physiological, molecular, agricultural, and environmental advances (1997-2003). Can. J. Microbiol. 50:521-577.

Blaha, D., Prigent-Combaret, C., Mirza, M. S., and Moënne-Loccoz, Y 2006. Phylogeny of the 1-aminocyclopropane-1-carboxylic acid deaminase-encoding gene $a c d S$ in phytobeneficial and pathogenic Proteobacteria and relation with strain biogeography. FEMS (Fed. Eur. Microbiol. Soc.) Microbiol. Ecol. 56:455-470.

Blakney, A. J. C., and Patten, C. L. 2011. A plant growth-promoting pseudomonad is closely related to the Pseudomonas syringae complex of plant pathogens. Microb. Ecol. 77:546-557.

Blasco, F., Iobbi, C., Giordano, G., Chippaux, M., and Bonnefoy, V. 1989 Nitrate reductase of Escherichia coli: Completion of the nucleotide sequence of the nar operon and reassessment of the role of the $\alpha$ and $\beta$ subunits in iron binding and electron transfer. Mol. Gen. Genet. 218:249-256

Blasco, F, Iobbi, C., Ratouchniak, J., Bonnefoy, V., and Chippaux, M 1990. Nitrate reductases of Escherichia coli: Sequence of the second nitrate reductase and comparison with that encoded by the narGHJI operon. Mol. Gen. Genet. 222:104-111.

Costechareyre, D., Rhouma, A., Lavire, C., Portier, P., Chapulliot, D., Bertolla, F., Boubaker, A., Dessaux, Y., and Nesme, X. 2010. Rapid and efficient identification of Agrobacterium species by recA allele analysis. Microb. Ecol. 60:862-872.

Creus, C. M., Graziano, M., Casanovas, E. M., Pereyra, M. A., Simontacchi, M., Puntarulo, S., Barassi, C. A., and Lamattina, L. 2005. Nitric oxide is involved in the Azospirillum brasilense-induced lateral root formation in tomato. Planta 221:297-303.

DeMoss, J. A., and Hsu, P. Y. 1991. NarK enhances nitrate uptake and nitrite excretion in Escherichia coli. J. Bacteriol. 173:3303-3310.

Dobbelaere, S., Croonenborghs, A., Thys, A., Ptacek, D., Vanderleyden, J., Dutto, P., Labandera-Gonzalez, C., Caballero-Mellado, J., Aguirre, J., Kapulnik, Y., Brener, S., Burdman, S., Kadouri, D., Sarig, S., and Okon, Y. 2001. Responses of agronomically important crops to inoculation with Azospirillum. Aust. J. Plant Physiol. 28:871-887.

Dobbelaere, S., Vanderleyden, J., and Okon, Y. 2003. Plant growth-promoting effects of diazotrophs in the rhizosphere. Crit. Rev. Plant Sci. 22:107-149.

El Zemrany, H., Cortet, J., Lutz, M. P., Chabert, A., Baudoin, E., Haurat, J., Maughan, N., Félix, D., Défago, G., Bally, R., and Moënne-Loccoz, Y. 2006. Field survival of the phytostimulator Azospirillum lipoferum CRT1 and functional impact on maize crop, biodegradation of crop residues, and soil faunal indicators in a context of decreasing nitrogen fertilization. Soil Biol. Biochem. 38:1712-1726.

Fages, J., and Mulard, D. 1988. Isolement de bactéries rhizosphériques et effet de leur inoculation en pot chez Zea mays. Agronomie 8:309-314.

Fremaux, B., Prigent-Combaret, C., and Vernozy-Rozand, C. 2008. Longterm survival of Shiga toxin-producing Escherichia coli in cattle effluents and environment: An updated review. Vet. Microbiol. 132:1-18.

Hamilton, R. H., and Fall, M. Z. 1971. The loss of tumor-initiating ability in Agrobacterium tumefaciens by incubation at high temperature. Experientia 27:229-230.

Hao, X., Xie, P., Johnstone, L., Miller, S. J., Rensing, C., and Wei, G. 2012. Genome sequence and mutational analysis of plant-growth-promoting bacterium Agrobacterium tumefaciens CCNWGS0286 isolated from a zinc-lead mine tailing. Appl. Environ. Microbiol. 78:5384-5394.

Hao, Y., Charles, T. C., and Glick, B. R. 2011. ACC deaminase activity in avirulent Agrobacterium tumefaciens D3. Can. J. Microbiol. 57:278286.

Herms, D. A., and Mattson, W. J. 1992. The dilemma of plants: To grow or defend. Q. Rev. Biol. 67:283-335

Hussain, H., Grove, J., Griffiths, L., Busby, S., and Cole, J. 1994. A sevengene operon essential for formate-dependent nitrite reduction to ammonia by enteric bacteria. Mol. Microbiol. 12:153-163.

Jacoud, C., Job, D., Wadoux, P., and Bally, R. 1999. Initiation of root growth stimulation by Azospirillum lipoferum CRT1 during maize seed germination. Can. J. Microbiol. 45:339-342.

Jensen, K. F. 1993. The Escherichia coli K-12 "wild types" W3110 and MG1655 have an rph frameshift mutation that leads to pyrimidine starvation due to low pyrE expression levels. J. Bacteriol. 175:3401-3407.

Krimi, Z., Petit, A., Mougel, C., Dessaux, Y., and Nesme, X. 2002. Seasonal fluctuations and long-term persistence of pathogenic populations of Agrobacterium spp. in soils. Appl. Environ. Microbiol. 68:33583365 .

Lassalle, F., Campillo, T., Vial, L., Baude, J., Costechareyre, D., Chapulliot, D., Shams, M., Abrouk, D., Lavire, C., Oger-Desfeux, C., Hommais, F., Guéguen, L., Daubin, V., Muller, D., and Nesme, X. 2011. Genomic species are ecological species as revealed by comparative genomics in Agrobacterium tumefaciens. Genome Biol. Evol. 3:762-781.

Lucy, M., Reed, E., and Glick, B. R. 2004. Applications of free living plant growth-promoting rhizobacteria. Antonie Leeuwenhoek 86:1-25.

Macdonald, H., and Cole, J. 1985. Molecular cloning and functional analysis of the cys $G$ and nirB genes of Escherichia coli K12, two closely-linked genes required for NADH-dependent nitrite reductase activity. Mol. Gen. Genet. 200:328-334.

Mark, G. L., Dow, J. M., Kiely, P. D., Higgins, H., Haynes, J., Baysse, C., Abbas, A., Foley, T., Franks, A., Morrissey, J., and O’Gara, F. 2005 Transcriptome profiling of bacterial responses to root exudates identifies genes involved in microbe-plant interactions. Proc. Natl. Acad. Sci. U.S.A. 102:17454-17459.

Miller, S. H., Browne, P., Prigent-Combaret, C., Combes-Meynet, E., Morrissey, J. P., and O'Gara, F. 2010. Biochemical and genomic comparison of inorganic phosphate solubilization in Pseudomonas species. Environ. Microbiol. Rep. 2:403-411.

Mohr, T. J., Liu, H., Yan, S., Morris, C. E., Castillo, J. A., Jelenska, J., and Vinatzer, B. A. 2008. Naturally occurring nonpathogenic isolates of the plant pathogen Pseudomonas syringae lack a type III secretion system and effector gene orthologues. J. Bacteriol. 190:2858-2870.

Mougel, C., Thioulouse, J., Perrière, G., and Nesme, X. 2002. A mathematical method for determining genome divergence and species delineation using AFLP. Int. J. Syst. Evol. Microbiol. 52:573-586.

Nautiyal, C., Rehman, A., and Chauhan, P. 2010. Environmental Escherichia coli occur as natural plant growth-promoting soil bacterium. Arch. Microbiol. 192:185-193.

Nelson, L. M., and Knowles, R. 1978. Effect of oxygen and nitrate on nitrogen fixation and denitrification by Azospirillum brasilense grown in continuous culture. Can. J. Microbiol. 24:1395-1403.

Noji, S., Nohno, T., Saito, T., and Taniguchi, S. 1989. The narK gene product participates in nitrate transport induced in Escherichia coli nitrate-respiring cells. FEBS (Fed. Eur. Biochem. Soc.) Lett. 252:139143.

Ponsonnet, C., and Nesme, X. 1994. Identification of Agrobacterium strains by PCR-RFLP analysis of pTi and chromosomal regions. Arch. Microbiol. 161:300-309.

Portier, P., Fischer-Le Saux, M., Mougel, C., Lerondelle, C., Chapulliot, D., Thioulouse, J., and Nesme, X. 2006. Identification of genomic species in Agrobacterium biovar 1 by AFLP genomic markers. Appl. Environ. Microbiol. 72:7123-7131.

Pothier, J. F., Wisniewski-Dyé, F., Weiss-Gayet, M., Moënne-Loccoz, Y., and Prigent-Combaret, C. 2007. Promoter-trap identification of wheat seed extract-induced genes in the plant-growth-promoting rhizobacterium Azospirillum brasilense Sp245. Microbiology 153:3608-3622.

Pothier, J. F., Prigent-Combaret, C., Haurat, J., Moënne-Loccoz, Y., and Wisniewski-Dyé, F. 2008. Duplication of plasmid-borne nitrite reductase gene nirK in the wheat-associated plant growth-promoting rhizobacterium Azospirillum brasilense Sp245. Mol. Plant-Microbe Interact. 21:831-842.

Prigent-Combaret, C., Blaha, D., Pothier, J. F., Vial, L., Poirier, M. A. Wisniewski-Dyé, F., and Moënne-Loccoz, Y. 2008 Physical organization and phylogenetic analysis of $a c d R$ as leucine-responsive regulator of the 1-aminocyclopropane-1-carboxylate deaminase gene acdS in phytobeneficial Azospirillum lipoferum 4B and other Proteobacteria. FEMS (Fed. Eur. Microbiol. Soc.) Microbiol. Ecol. 65:202-219.

Raaijmakers, J., Paulitz, T., Steinberg, C., Alabouvette, C., and MoënneLoccoz, Y. 2009. The rhizosphere: A playground and battlefield for soilborne pathogens and beneficial microorganisms. Plant Soil 321:341361.

Raio, A., Peluso, R., Nesme, X., and Zoina, A. 2004. Chromosomal and plasmid diversity of Agrobacterium strains isolated from Ficus benjamina tumors. Eur. J. Plant Pathol. 110:163-174.

Rezzonico, F., Zala, M., Keel, C., Duffy, B., Moënne-Loccoz, Y., and Défago, G. 2007. Is the ability of biocontrol fluorescent pseudomonads to produce the antifungal metabolite 2,4-diacetylphloroglucinol really synonymous with higher plant protection? New Phytol. 173:861872.

Richardson, A., Barea, J. M., McNeill, A., and Prigent-Combaret, C. 2009. Acquisition of phosphorus and nitrogen in the rhizosphere and plant growth promotion by microorganisms. Plant Soil 321:305-339.

Rodríguez, H., Fraga, R., Gonzalez, T., and Bashan, Y. 2007. Genetics of phosphate solubilization and its potential applications for improving plant growth-promoting bacteria. Dev. Plant Soil Sci. 102:15-21.

Rondon, M. R., Ballering, K. S., and Thomas, M. G. 2004. Identification and analysis of a siderophore biosynthetic gene cluster from Agrobacterium tumefaciens C58. Microbiology 150:3857-3866.

Rosenberg, C., and Hughet, T. 1984. The pAtC58 plasmid of Agrobacte rium tumefaciens is not essential for tumor induction. Mol. Gen. Genet. 196:533-536.

Sambrook, J., Fritsch, E. F., and Maniatis, T. 1989. Molecular Cloning: A Laboratory Manual. Cold Spring Harbor Laboratory Press, Cold Spring Harbor, NY, U.S.A. 
Sanguin, H., Herrera, A., Oger-Desfeux, C., Dechesne, A., Simonet, P., Navarro, E., Vogel, T. M., Moënne-Loccoz, Y., Nesme, X., and Grundmann, G. L. 2006a. Development and validation of a prototype 16S rRNA-based taxonomic microarray for Alphaproteobacteria. Environ. Microbiol. 8:289-307.

Sanguin, H., Remenant, B., Dechesne, A., Thioulouse, J., Vogel, T. M., Nesme, X., Moënne-Loccoz, Y., and Grundmann, G. L. 2006b Potential of a $16 \mathrm{~S}$ rRNA-based taxonomic microarray for analyzing the rhizosphere effects of maize on Agrobacterium spp. and bacterial communities. Appl. Environ. Microbiol. 72:4302-4312.

Sanguin, H., Kroneisen, L., Gazengel, K., Kyselková, M., Remenant, B., Prigent-Combaret, C., Grundmann, G. L., Sarniguet, A., and MoënneLoccoz, Y. 2008. Development of a 16S rRNA microarray approach for the monitoring of rhizosphere Pseudomonas populations associated with the decline of take-all disease of wheat. Soil Biol. Biochem. 40:1028-1039.

Sharifi-Tehrani, A., Zala, M., Natsch, A., Moënne-Loccoz, Y., and Défago, G. 1998. Biocontrol of soil-borne fungal plant diseases by 2,4-diacetylphloroglucinol-producing fluorescent pseudomonads with different restriction profiles of amplified $16 \mathrm{~S}$ rDNA. Eur. J. Plant Pathol. 104:631-643.

Tenaillon, O., Skurnik, D., Picard, B., and Denamur, E. 2010. The population genetics of commensal Escherichia coli. Nat. Rev. Microbiol. 8:207-217.

Texier, S., Prigent-Combaret, C., Gourdon, M. H., Poirier, M. A., Faivre, P., Dorioz, J. M., Poulenard, J., Jocteur-Monrozier, L., Moënne-Loccoz, Y., and Trevisan, D. 2008. Persistence of culturable Escherichia coli fecal contaminants in dairy alpine grassland soils. J. Environ. Qual.
37:2299-2310.

Walker, V., Bertrand, C., Bellvert, F., Moënne-Loccoz, Y., Bally, R., and Comte, G. 2011. Host plant secondary metabolite profiling shows a complex, strain-dependent response of maize to plant growth-promoting rhizobacteria of the genus Azospirillum. New Phytol. 189:494506.

Walker, V., Couillerot, O., Von Felten, A., Bellvert, F., Jansa, J., Maurhofer, M., Bally, R., Moënne-Loccoz, Y., and Comte, G. 2012. Variation of secondary metabolite levels in maize seedling roots induced by inoculation with Azospirillum, Pseudomonas and Glomus consortium under field conditions. Plant Soil 356:151-163.

Yang, K., and Metcalf, A. A. 2004. A new activity for an old enzyme: Escherichia coli bacterial alkaline phosphatase is a phosphite-dependent hydrogenase. Proc. Natl. Acad. Sci. U.S.A. 101:7919-7924.

Yokoyama, K, and Suzuki, M. 2005. Orthologous and paralogous FFRPs in E. coli and related proteobacteria. Proc. Jpn. Acad. Ser. B. 81:129139.

Zdobnov, E. M., and Apweiler, R. 2001. InterProScan-an integration platform for the signature-recognition methods in InterPro. Bioinformatics 17:847-848.

Zhang, J., Boone, L., Kocz, R., Zhang, C., Binns, A. N., and Lynn, D. G. 2000. At the maize/Agrobacterium interface: Natural factors limiting host transformation. Chem. Biol. 7:611-621.

\section{AUTHOR-RECOMMENDED INTERNET RESOURCE}

R Project for Statistical Computing software: www.r-project.org 